\title{
Poesía sonora, arte sonoro: un acercamiento a sus procesos de semiosis
}

\author{
Susana González Aktories
}

En este ensayo se argumenta desde una perspectiva intersemiótica, pero también y sobre todo desde la trinchera disciplinar de la literatura, a favor de un reconocimiento de la poesía sonora. Se presentan algunas de sus características más representativas, así como la relación que guarda con la poesía visual y con la música, y se argumenta acerca de su gradual emancipación de la página y del soporte escrito para explorar su potencial expresivo gracias a las técnicas de reproducción sonora. Su vínculo con el arte sonoro y las estrategias empleadas en este tipo de creaciones son ilustrados brevemente mediante ejemplos extraídos del contexto mexicano.

PALABRAS CLAVE: oralidad, poesía sonora, arte sonoro, literatura y música, semiótica.

From an inter-semiotic perspective, this paper argues in favor of the recognition of sound poetry as a category in the literary studies. Some of the main features of sound poetry and its links with visual poetry and music are examined here, aiming for a comprehension of the gradual release of this form of poetry from the page and the written support, and for an exploration of its expressive potential based on technology for sound reproduction. Its links with other kinds of sound art and the strategies it uses are illustrated briefly through some examples of the Mexican context. 

Susana González Aktories

Facultad de Filosofía y Letras, UNAM

\section{Poesía sonora, arte sonoro:}

\section{un acercamiento a sus procesos de semiosis}

Visualizar el sonido de un signo es deducir lo audible de lo que se percibe a la vista de lo legible

Michel CHION

Literatura oral y sonido desde la academia:

hacia la definición de un nicho para el arte sonoro

Los estudios literarios hoy en día siguen presos de algunos paradigmas heredados de la tradición occidental cuando se trata de reconocer el valor sonoro de la literatura: unos, al tratarlo como una reliquia de la era clásica en la que, tanto en la praxis como en la teoría, palabra, sonido y gesto se constituían como un solo discurso. Otros, al remontarse a los cancioneros medievales y a la lírica popular como manifestaciones en las que verbo y música armonizaban; otros más, cuando resaltan el carácter predominantemente oral del gesto literario en el Renacimiento. Están también quienes reconocen nuevas formas de oralidad literaria en las estrategias retóricas empleadas en el siglo xIx y orientadas, más que a apelar al amplio público 
en foros y espacios abiertos, a comunicar desde la exclusividad de los salones literarios de la alta burguesía. Finalmente, están quienes consideran que la esencia oral y sonora de la literatura se vio en crisis debido al impacto social de la imprenta, que convertía la comunicación literaria en una praxis cada vez más alejada de la oralidad, instaurándose en la intimidad silenciosa impuesta por la lectura individual del texto escrito.

Contados son todavía los estudios que analizan a profundidad las formas en las que se ha mantenido o aun en las que ha resurgido el valor oral de la literatura, ${ }^{1}$ particularmente en las propuestas de vanguardia de principios del siglo xx tales como la poesía fonética, o por ejemplo en los performances poéticomusicales de los beatniks a mediados del mismo siglo. ${ }^{2}$

Respecto a la praxis oral de la literatura, en concreto de la poesía, además de la ramificación que en el ámbito de la lírica se ha desarrollado y robustecido como "música popular" gracias a los medios de comunicación y al creciente mercado discográfico y digital, ${ }^{3}$ se siguen promoviendo como antaño recitales poéticos; se continúan editando colecciones fonográficas de lectura en

${ }^{1}$ Uno de los estudios que revaloró de forma notable la faceta oral de la poesía fue el de A.B. Lord, que aparece como entrada a "Oral poetry" en la Princeton Encyclopedia of Poetry and Poetics. En décadas recientes fueron Ruth Finnegan (Oral Poetry), Walter Ong (Oralidad y escritura) o Paul Zumthor (Introducción a la poesía oral) quienes se preocuparon por el estudio de la poesía oral. Cabe mencionar en este sentido también la aparición más reciente de la compilación de textos de D. R. Olson y N. Torrance, Cultura escrita y oralidad, o del trabajo de Ricardo Senabe, "Poesía y oralidad".

${ }^{2}$ Recuérdese el particular interés mostrado por Jack Kerouac, William Burroughs o Allen Ginsberg en hacer de la lectura un acto social, sonoro, cuyo desarrollo discursivo se encontraba en diálogo con la improvisación musical, siendo el jazz una de las fuentes importantes de inspiración.

${ }^{3}$ Una importante parte de su desarrollo se ha degradado a discurso artístico de segundo orden, desvirtuado por el prejuicio de lo comercial y mercadológico de la "lírica pop masiva", tema que se delega generalmente a los estudios etnomusicológicos. 
"voz viva" de autores consagrados; se organizan tertulias bohemias que incluso derivan en maratones de poesía conocidos como poetry slams $;{ }^{4}$ se realizan festivales de poesía en voz alta, ${ }^{5}$ en donde se presentan diversos tipos de géneros orales (spoken art forms), que van desde los ejercicios ya convencionales de la poesía fonética u optofonética hasta la poesía performer rap, el spoken word, el hip-hop, los poecantos, la poesía multimedia, el spoken video y la poesía sonora. Sin embargo, la academia literaria ha permanecido en gran medida silente de cara a este tipo de producción.

Si bien los gestos de oralidad se comienzan a asomar como un "artificio" estilístico-literario que se ha puesto de moda estudiar sobre todo en el ámbito de la narrativa, lo cierto es que la literatura oral e intermedial sigue siendo un tema marginal. En este marco, la poesía sonora se ha reconocido si acaso todavía como un ejercicio meramente experimental, aun provocador, cuyo valor literario ha sido relativizado y cuestionado. Una prueba de ello es que el oficio creador del poeta sonoro se confunde y se funde por momentos con el del ingeniero de sonido, el del artista plástico que realiza instalaciones sonoras, o el del músico de formación electroacústica. A decir de Manuel Rocha, catedrático y artista sonoro mexicano, en este campo se pueden hacer diferenciaciones todavía más específicas, reveladoras de una gama de intenciones que van de lo más musical hasta lo más plástico, pasando por lo esencialmente poético. Dentro de esta clasificación están, por ejemplo, las

\footnotetext{
${ }^{4}$ Nombre con el que se conoce al movimiento abanderado por Marc Smith en Chicago a finales de los años setenta y principios de los ochenta.

${ }^{5}$ Poesía en voz alta, nombre que en México lleva el festival que desde hace cuatro años se está realizando en forma anual en la Casa del Lago de la ciudad de México y que, a decir de los organizadores, retoma las prácticas difundidas en los años setenta y ochenta por escritores como Juan García Ponce, Octavio Paz, Tomás Segovia o José Luis Ibáñez. Dicho tipo de encuentro fue resucitado después de haber caído en el olvido por más de una década.
} 
músicas electroacústica, electrónica y experimental, el paisaje sonoro, el radio arte, la escultura sonora, la instalación sonora, las acciones sonoras, los intermedia y los poemas sonoros. ${ }^{6}$ Las expresiones de poesía sonora, sin importar la naturaleza de su intención poiética, se han refugiado así, junto con aquéllas de las artes plásticas y las de las búsquedas musicales, en el todavía ambiguo nicho intermedial del "arte sonoro".

Afinidades, herencias y ad-herencias de la poesía sonora

Si bien es identificada como parte del genérico "arte sonoro", en la base del discurso y de la identidad de la poesía sonora está el vínculo declarado con la tradición literaria. Pero no de aquélla cuyo origen estaría naturalmente asociado a la poesía oral de corte tradicional, y que es por lo demás también considerada fuente primaria del desarrollo musical. ${ }^{7}$

La poesía sonora se dice heredera de los movimientos artísticos de las primeras décadas del siglo pasado. Entre ellos, de las exploraciones de la poesía simbolista francesa, la literatura futurista rusa, los ejercicios literarios de los surrealistas, ${ }^{8}$ la poesía fonética, las obras de los dadaístas y la poesía concreta alemana. Lo que ha interesado a los poetas sonoros actuales de la tan variada como amplia producción de todos estos grupos ha sido, además de su trasgresión, su riqueza en exploraciones de formas de expresión hasta entonces poco habituales o aun desconocidas, algunas desde la concreción de la poesía visual

${ }^{6}$ Manuel Rocha, "Arte sonoro en México", texto del folleto del disco compacto correspondiente al núm. 7 de RAS. Revista de Arte Sonoro.

${ }^{7}$ A decir de musicólogos como Charles Rosen, hasta la mitad del siglo XVIII la música comúnmente conocida era de tipo vocal, tanto sacra como seglar (cfr. Rosen, Sonata Forms, 8).

${ }^{8}$ Recordemos, además, la labor realizada por Antonin Artaud para la radio a finales de los años cuarenta. 
en su expresión gráfica en el papel; otras, a partir de la potencial evocación que en lo escrito se hacía de lo sonoro, todas con la intención de afirmarse y de proponer desde espacios liminales nuevas formas de representación de lo poético.

A pesar de que muchas de estas expresiones querían ser, como decía el músico-poeta dadaísta Kurt Schwitters, "poesía de los sonidos", ${ }^{9}$ las obras permanecían fuertemente ancladas al silencioso signo escrito: en un interesante juego intersemiótico, el signo poético sonoro, que buscaba el sonido como su centro de atención, paradójicamente mantuvo una fuerte identidad de tipo gráfico antes que sonoro, apoyándose, al menos en una primera etapa, en el signo gráfico — verbal y no-verbal-, en tanto referente o notación para su interpretación en la esfera de lo acústico.

En una segunda etapa, la de una oralidad renovada y refuncionalizada cada vez más por la reproductibilidad tecnológica basada en una técnica y de ahí en una gramática del registro, la reproducción y la manipulación sonora, el poeta se apartó cada vez más de la torre de marfil en función del estudio o laboratorio de sonido; abandonó la pluma y el papel por sofisticadas computadoras y aparatos electrónicos con los que podía replantear la noción del tono poético desde su esencia sonora. En una tercera etapa incluso se aventuró aún más allá de la propia voz para fungir como "oído lírico" de otras voces, artífice de aquel signo sonoro - incluyendo el incidental - que fuera susceptible de ser escuchado "poéticamente". ${ }^{10}$ Así, esta poesía comenzó a mostrar una faceta que ya no sólo vinculaba lo escrito y visual con lo sonoro, ni pretendía ser de orden vocal - expresión humana-, sino que abarcaba lo humanamente asimilable del amplio mundo sonoro — expresión humanizada.

${ }^{9}$ Así lo predicaban también quienes hacían poesía fonética.

${ }^{10}$ Una clasificación similar en tres etapas es justificada por Philadelpho Menezes en "Tres momentos históricos y cuatro tendencias de hoy en la poesía sonora" (apud Bulatov, Homo sonorus, 247-254). 
La nueva notación musical

y sus paralelismos con la poesía sonora

El sendero abierto por la poesía sonora, desde su libertad gráfica y acústica, se cruza con un camino de una tradición distinta, la musical que, a pesar de los paralelismos con esta poesía, se fue formulando a partir de necesidades y paradigmas diferentes.

Conviene aquí plantear un brevísimo panorama de lo acontecido en la esfera de lo musical para entender cómo en la actualidad la poesía sonora y el arte sonoro han coincidido en algunos de sus planteamientos y sus búsquedas.

Influida también por la escritura, cuyo impacto se hizo notar sobre todo a partir del siglo XVIII, la música tonal desarrollada en Occidente hizo de la notación un sistema de codificación convencional y relativamente estable hasta los inicios del siglo xx. Dicha notación, en la medida en que logró asir gráficamente determinados parámetros de lo sonoro, se volvió texto "legible" de la obra musical, haciéndola inteligible al permitir conocerla mediante la lectura mental, aunque no se llegara a interpretar musicalmente. ${ }^{11}$ Sin embargo, pronto se reconocieron las limitaciones de este sistema al no lograr captar en su totalidad la riqueza del signo sonoro. Por ejemplo, tal como comenta Michel Chion, una partitura clásica para piano "no transcribe el sonido del piano, ni describe su desarrollo característico ni su timbre". ${ }^{12}$ Las características del discurso musical son evidenciadas sólo parcialmente, esto es, la altura, la duración (considerando que ésta varía según el tempo indicado) y la intensidad, sirviéndose incluso del discurso verbal ya sea para indicar con qué tipo de instrumento se debe interpretar la obra, para adjetivar algunos de sus gestos o intenciones (crescendo, descendendo, rubato, animato, andante, etc.), o bien para dar

${ }^{11}$ Michel Chion, El sonido. Música, cine, literatura, 357.

${ }^{12}$ Michel Chion, El sonido. Música, cine, literatura, 357. 
identidad y nombre a la pieza. Por lo demás, este tipo de partitura exige una competencia adicional del intérprete en cuanto al estilo y género en el que se inscribe determinada obra que muchas veces no queda manifiesta en la partitura. ${ }^{13}$

Sin embargo, cuando la música comienza a liberarse de la tonalidad y del pentagrama, la notación musical deviene signo de una insinuación sonora, muchas veces aleatoria; es decir, se vuelve signo de lo posible, activado por el ingenio del compositor y decodificado por el intérprete con la debida creatividad y capacidad lúdica con la que logra reactivar en cada interpretación el sentido de la misma.

Este tipo de composiciones, por su refuncionalización notacional, se ha acercado, a la manera en la que también lo hizo la poesía visual y luego sonora, a las artes gráficas y a la concepción del espacio en papel tal como se proyectaría desde la sugerida tridimensionalidad de un plano arquitectónico, cosa que a su vez ha exigido del intérprete una renovada competencia audio-lectora: al deconstruirse la partitura tradicional, se ha construido una nueva posibilidad combinatoria de sonidos, pero sobre todo se ha expandido el espectro de la representación del objeto sonoro, lo que ha demandado una nueva mirada sobre estos mapas sonoros con el fin de reorientar ya no sólo el punto de vista sino el "punto de escucha". Estas atrevidas grafías hablan así también de la perspectiva sonora como una nueva forma simbólica de representación.

Es notable, por su parte, que tanto la representación de la partitura tradicional como las nuevas formas de notación sonora realizadas a partir de programas cibernéticos, han influido a la poesía visual y sonora, y se han constituido muchas veces en modelo, y otras en código sígnico prestado con el que icónicamente (aun a partir de alusión y desarticulación de imá-

${ }^{13}$ Este es uno de los argumentos más importantes en torno a los cuales Robert Hatten formula sus ideas sobre el gesto musical en su estudio Musical Meaning in Beethoven: Markedness, Correlation and Interpretation. 
genes convencionales como los pentagramas y las formas de representación de las notas musicales, etc.) se ha expandido el sentido poético, más allá del signo verbal, reforzando el espíritu sonoro y libre —en un sentido sobre todo conceptual — del poema. ${ }^{14}$

\title{
Hacia la concreción de la nueva poesía sonora
}

\author{
poema siempre en construcción montaje/desmon- \\ taje/andamio/ \\ autopista anfibia supercarretera \\ hacia lo que no/ así es que nohay, \\ nuai/ renuncio a lo ido \\ ("No hay poema", autor desconocido) ${ }^{15}$
}

Además de los guiños gráficos y visuales, entre las diversas estrategias que ha adoptado la poesía sonora en su desarrollo durante las últimas décadas - tanto la que se ha proyectado en papel como de la que se ha ejecutado para su reproducción sonora-, se pueden resaltar de manera somera cinco grandes ejes: ${ }^{16}$

\footnotetext{
${ }^{14}$ Algunos ejemplos representativos los constituyen propuestas tales como "New music" de Sarenco (1971), el "Pentahexagrama para John Cage" de Augusto de Campos (1977), "Music for Stara" de Dick Higgins (s.f., años ochenta), "Pseudoscore" de Giulia Niccolai (1984), "Duet for Anette" de Steffen Mezger (1988), "Dietpoem" de Avelino de Araujo (1989), "Sound Poem" de Giovanni Fontana (1996) y "Blacks in Concert" de J.M. Calleja (1996). Estos y otros poemas han sido recogidos en antologías de poesía sonora y experimental como la de Dmitry Bulatov (2004) o la de Fernando Millán y Jesús García Sánchez (Escritura en libertad. Antología de poesía experimental, Madrid, Visor Libros, 2005 [ed. original 1975]).

$15<$ http://nohaypoema.blogspot.com/2004_04_11_archive.html>, consultada en febrero de 2008.

${ }^{16}$ Retomo aquí sólo parcialmente la clasificación elaborada por Dick Higgins, dado que algunos de sus parámetros no parecen suficientemente diferenciadores. Queda pendiente una tipología exhaustiva de los distintos rasgos de la poesía sonora. (Cfr. Higgins, "Cuatro puntos hacia una taxonomía de la poesía sonora" en Bulatov, Homo sonorus, 27-38).
} 
- La creación de cuerpos sonoros a partir de juegos de palabras.

- La creación de un lenguaje inventado, incomprensible, cuyo particular interés está en la textura fónica derivada de la libre combinación de consonantes y vocales. ${ }^{17}$

- La potenciación de la musicalidad como parte del timbre y la dinámica de la prosodia verbal, ya sea por la exageración de gestos del habla, por juego con el volumen, con el tono y aun con la identidad derivada de la voz, misma que puede encarnar tanto una edad y un género determinados como intenciones comunicativas y estados de ánimo claramente diferenciados. ${ }^{18}$

- La integración de sonidos subsidiarios, incidentales, que por momentos se vuelven el centro de atención del poema (imagen sonora, paisaje sonoro).

- La inclusión deliberada de la música como código semiótico paralelo o complementario al discurso verbal ( $\sin$ buscar que se vuelva una canción).

En lo que toca al registro escrito, podemos encontrar ejemplos sobre todo referentes a los primeros tres puntos, a lo que habría que añadir la graficación que, muchas veces gracias a las computadoras, se ha hecho de algunos poemas en tanto cuerpos sonoros y que se asemejan a las graficaciones hechas de composiciones musicales electroacústicas.

Los poemas y sus versos se han vuelto, así, "proyectivos", en un sentido visual-expresivo que trasciende los formatos

${ }^{17}$ Cuando existe un registro escrito de dichas obras, el texto muestra configuraciones sonoras poco convencionales para los lenguajes verbales, entre las que destaca la repetición exagerada de una vocal o la aglutinación de múltiples vocales o consonantes, que se vuelven difícilmente pronunciables.

${ }^{18}$ Cuando existe un registro escrito, se emplea una combinación tipográfica múltiple, con tamaños de letra que contrastan entre sí, a veces de forma desmedida, y haciendo un despliegue deliberado del texto en la página, con lo que pretende ilustrar, más que el contenido semántico de las palabras, el tipo de énfasis buscado en la expresión sonora. 
poéticos más tradicionales. Podría considerarse entonces que la experiencia sensible, en su sentido más amplio, sinestésico e integrador, se vuelve el eje motor así como la esencia de estas identidades poéticas.

Además de las características ya señaladas, cabe agregar una esencial e intrínseca de formas de arte también llamado alternativo, al que se afilia la poesía sonora: la "experimentación”, misma que apunta a su valor lúdico, de obra abierta. Sin embargo, este atributo se ha vuelto un arma de doble filo, en tanto frecuentemente ha degradado lo experimental a la categoría de ejercicio improvisado, provisional, poco serio, y aun amorfo, cosa que sin duda ha afectado su credibilidad y la apuesta de la crítica a ver en estas obras el germen de una nueva tradición poética y de una actitud de "lectura" diferente que demanda una atención menos logocéntrica, más visual y auditiva de la obra poética.

Además de lo anterior, si se asume la propuesta de Dick Higgins de ubicar a la poesía sonora en el campo de los llamados "intermedia", 19 se podrá reconocer la enorme riqueza semiótica que alberga esta concepción poética "anfibia" que, sin alterar su esencia, puede ser experimentada ya sea como objeto plástico, objeto musical u objeto poético, o como la combinación de varios de éstos, dependiendo de la intención e identidad de su creador, de la destreza (en su caso) del mediador o intérprete, del contexto en el que uno se expone a estas obras, y de la competencia que se tiene para leerlas, verlas o escucharlas. La materia sonora como materia maleable que se adapta a la

19 "Intermedia Chart” de Dick Higgins, 1995, gráfica reproducida en la antología de Dmitry Bulatov, Homo sonorus, 248. Se trata de una esquematización que representa diferentes esferas de creación artística que conviven unas con otras de manera independiente y que en algunos casos comparten áreas a manera de intersecciones. En el centro de dicha gráfica se encuentran: "Action music", "Happenings", "Object Music", "Sound poetry"; y en una circunferencia más amplia, "Poesía visiva", "Concrete poetry", "Mail art", "Conceptual art", "Performance art", "Dance theatre", "Science art". Todas estas esferas están englobadas ya sea total o parcialmente dentro del amplio campo de los "Intermedia". 
esencia de cada uno de estos discursos (confiriéndole su espíritu en tanto cuerpo sonoro), se adapta fácilmente a los distintos medios y funge como elemento vinculador, inter-discursivo.

Como resultado de lo anterior, es notable que la poesía sonora esté apartándose cada vez más de la escritura y de la poesía visual, fundando, gracias a los malabares electroacústicos, una nueva forma de oralidad. Así, cuando antes se encontraban publicaciones de poemas sonoros en las que el texto escrito aludía al sonido o en el mejor de los casos iba acompañado de un disco (a manera de audiolibro), ahora la poesía sonora se ha vuelto signo cada vez más "sonoro", audible, emancipándose del espacio gráfico y escrito. Esto es notable en antologías como Writing Aloud (2001), Homo Sonorus (2001), o The Spoken Word Revolution (2004), en las que los textos escritos rara vez contienen la transcripción misma de la obra poética sonora, sino presentan paratextos o metatextos del material auditivo, esto es, títulos o textos periféricos, complementarios, metadiscursivos, que se centran en declarar la poética de su autor, en contextualizar su obra, o en explicar tanto los principios como el proceso creador, ofreciendo así un programa o una orientación para la experiencia sonora. ${ }^{20}$

\section{Coda:}

poesía sonora en diálogo con el arte sonoro

Toda poesía relaciona el tiempo, el espacio el sonido con la experiencia.

Dick HigGins

He hablado hasta ahora de la cercanía notable que hay entre las diversas "artes sonoras" en el devenir (ya casi de un siglo)

\footnotetext{
${ }^{20}$ Entre los estudios propiamente académicos destinados a esta materia cabe resaltar el libro de Javier Ariza, Las imágenes del sonido (2003).
} 
de su continua experimentación. Por último podemos asomarnos a otros fenómenos en los que la poesía y el arte sonoro se comunican y enriquecen. Para ello se tomarán a continuación algunos ejemplos de piezas relativamente conocidas, extraídas del contexto mexicano, ${ }^{21}$ para observar cómo los artistas plásticos y los músicos han abrevado de la materia poética, al grado de hacerla suya mediante diversos procesos dialógicos. ${ }^{22}$

Comencemos por revisar el caso de "Pocos cocodrilos locos", un poema concreto en su origen, creado por Mathias Goeritz, artista plástico alemán radicado en México, con el que revistió en 1965, a manera de mural de piedra blanca en relieve, un edificio en la calle de Niza de la ciudad de México ${ }^{23}$ y que casi treinta años después (1998) fue motivo de inspiración para el músico Manuel Rocha, quien empleó el texto verbal como materia para su propio "poema sonoro". Aquí la referencia "poética" de base se da en primera instancia a nivel metadiscursivo, en el sentido de que ambos creadores, sin asumirse como poetas, involucran en su creación un discurso que ellos mismos identifican como poético. Esto en lo que se refiere a la definición de sus intenciones, pero también cabe reconocer que en esta apropiación se mantiene una identidad esencialmente verbal del discurso poético, que en un caso se plasma como materia plástica y en el segundo se vuelve materia sonora, desarrollada a partir del

${ }^{21}$ Sobre la evolución del arte sonoro en México hay trabajos interesantes publicados por diversos autores en revistas tales como Pauta, particularmente los números 100 y 102 dedicados al arte sonoro y a la poesía sonora, respectivamente; y Curare, cuyos números 23 y 25 contienen artículos de Manuel Rocha sobre arte sonoro.

${ }^{22}$ Los ejemplos fueron tomados de la compilación realizada por Manuel Rocha para el segundo disco compacto contenido en el núm. 7 de RAS. Revista de Arte Sonoro. En cuanto a otras ediciones fonográficas sobre arte sonoro en México, consúltense los 3 discos producto de los tres primeros Festivales Internacionales de Arte Sonoro, editados por Manuel Rocha y Miguel Hernández y producidos por el Ex Teresa Arte Actual, Consejo Nacional para la Cultura y las Artes, Instituto Nacional de Bellas Artes, 1999, 2000 y 2001, respectivamente, así como el disco compacto Personae/Poesía Mexicana y Electroacústica, producido por Motín Poeta en 2006.

${ }^{23}$ De dicho mural actualmente sólo quedan registros fotográficos. 
juego de palabras y de su progresión combinatoria mediante la manipulación sonora, que permite explorar posibilidades expresivas de la propia prosodia, del ritmo de las repeticiones, así como del tejido fónico que se produce por la superposición de fragmentos de la grabación, todo lo cual genera el atractivo cuerpo sonoro en la composición de Rocha.

En un sentido similar de referencia inicialmente metadiscursiva opera el poema "Maneje con precaución" (aproximadamente 1973) del artista plástico Felipe Ehrenberg, al anunciarse como parte de la pieza que lo que se recitará es un "poema sonoro" (nuevamente se impone el género y la intención sobre el objeto). Lo que le sigue parece una grabación realizada durante un trayecto en auto, en el que, a la par de la lectura realizada de los carteles y anuncios callejeros por el sujeto poético y alternada con fragmentos descriptivos y hasta sentenciosos del paisaje urbano, se escucha el ruido de fondo producido por el transitar a lo largo de la calle. La prosodia sonora, que aparentemente se produce de manera espontánea, genera un ritmo sintáctico apoyado en fórmulas enumerativas, y gestualmente permite modular la voz para hacerla encarnar, por momentos, incluso identidades alternas, como la de un vendedor ambulante o merolico.

El tercer ejemplo, "Hamlet for Two Voices" (1977) del artista conceptual mexicano Ulises Carrión, parte de una referencialidad paratextual, en la que dos voces, identificadas como femenina y masculina respectivamente, se alternan en la lectura exclusiva de los nombres correspondientes a los personajes que aparecen en una escena del Hamlet shakesperiano. Si se desconoce el título, intriga de inicio el orden aparentemente aleatorio de la sucesión de nombres, generando un tejido sonoro parecido al de Carl Orff en sus piezas vocales infantiles, dominadas por la periodicidad y el ritmo creado por la articulación sucesiva de sustantivos (en este caso de nombres de personajes), respetando su acentuación natural. La esencia alusiva al drama 
shakesperiano sólo se evidencia cuando aparecen hacia la mitad de la grabación las primeras menciones a Hamlet, personaje clave e inconfundible que condensa la referencia intertextual, haciendo que la escucha se reoriente, focalizándose en la relación de los personajes con la obra teatral, con lo cual se genera un giro en la significación del tejido sonoro.

El último ejemplo es "La salvaje costumbre", de Victor Manuel Dávalos, artista que se destacó por sus creaciones de radioarte. La primera relación se da a través del título, que remite al poema del chiapaneco Jaime Sabines. A esto se suma el efecto sinecdótico de reconocer la voz misma de este poeta que en vida fue muy popular y quien ofreció muchos recitales de poesía. En la pieza se encuentran reproducidos los versos del poema; sin embargo, gradualmente sufren una distorsión sonora, creando efectos sónico-semánticos que evidencian la interpretación que del ambiente y del tono del poema tiene el propio Dávalos. Además, añade sonidos instrumentales, por ejemplo de percusiones y de violoncello, con los que logra efectos colorísticos que contribuyen a dar cuerpo al texto verbal reproducido.

Hasta aquí una breve exploración de procesos intertextuales de corte literario en el marco del arte sonoro. Como puede apreciarse, se precisa de una descripción casi fenomenológica de las condiciones de cada una de las obras para llegar a concebir su poética así como las maneras tan diferentes en las que estos productos de inspiración poética y literaria relacionan el tiempo, el espacio y el sonido con la experiencia.

Acercamientos conciliadores y a la vez exhaustivos, como los que podrían ofrecer los estudios intersemióticos, ayudarían quizá a legitimar estos discursos poéticos, que por tantas décadas se han mantenido en los márgenes de lo estrictamente literario, y podrían mostrar que no sólo es deseable sino también necesario estudiar con la debida seriedad y distancia crítica la poesía sonora en el marco del arte sonoro. El primer paso lo han dado ya los propios poetas, quienes se han comportado a 
la vez como creadores y teorizadores de su propia obra. Si se revisa la riqueza que ésta alberga en sus distintos niveles de significación y de lectura (desde la visual hasta la sonora), seguramente se encontrarán muchas claves más para entender el rumbo que ha adoptado la poesía sonora y vislumbrar cómo se abre camino en lo que está por venir.

El estudio de la poesía sonora en el ámbito disciplinar de la literatura puede sin duda mostrar el modo en que el género - poesía - ha sido enriquecido con formas novedosas de pensar la propia creación poetica, sin dejar de ratificar su esencia poética en un sentido amplio y generoso y, más importante aún, puede ayudar a comprender las razones de dichas transformaciones, movidas por un genuino gesto poético. 


\section{REFERENCIAS}

ArIZA, Javier, Las imágenes del sonido, Cuenca, Universidad de Castilla la Mancha, 2003.

Bosseur, Jean-Yves, Du son au signe. Histoire de la notation musicale, Paris, Éditions Alternatives, 2005.

Bulatov, Dmitry (comp.), Homo sonorus. Una antología internacional de poesía sonora [2001, en inglés], México, Radio Educación-Conaculta-Instituto Nacional de Bellas Artes, 2004.

Chion, Michel, El sonido. Música, cine, literatura, Barcelona, Paidós, 1999.

Dibelius, Ulrich, Moderne Musik nach 1945, Bonn, Piper, 1997.

Eleveld, Mark (ed.), The Spoken Word Revolution (Slam, Hip Hop \& the Poetry of a New Generation) [más disco compacto], Naperville [Illinois], Soundbooks Mediafusion, 2004.

Finnegan, Ruth, OralPoetry. Its Nature, Significance and Social Context [1977], Bloomington e Indianapolis, Indiana University Press, 1992.

Hatten, Robert S., Musical Meaning in Beethoven: Markedness, Correlation and Interpretation, Indianapolis, Indiana University Press, 1994.

LaBelle, Brandon y Christof Migone (ed.), Writing Aloud. The Sonics of Language, New York, Errant Bodies Press-Ground Fault Recordings, 2001.

Ong, Walter J., Oralidad y escritura, México, Fondo de Cultura Económica, 1982.

Rocha, Manuel, "Arte sonoro en México", texto del folleto del disco compacto correspondiente a RAS. Revista de Arte Sonoro 7 , Universidad de Castilla-La Mancha, Centro de Creación Experimental-Facultad de Bellas Artes, 2004.

Rosen, Charles, Sonata Forms, New York, New Norton, 1980.

TARasti, Eero, "Voice and Identity", en Signs of Music. A Guide to Musical Semiotics, Berlin-New York, Mouton de Gruyter, 2002, 157-177.

WüRFEL, Stefan Bodo, Das deutsche Hörspiel, Stuttgart, Metzler Verlag, 1978.

ZumThor, Paul, Introducción a la poesía oral, Madrid, Taurus, 1991 (Humanidades). 